\title{
Modeling the Deposition of Metal Atoms on a p-Type Organometallic Conductor: Implications for Stability and Electron Transfer
}

\author{
Bhaskar Chilukuri ${ }^{\dagger}$ and Thomas R. Cundari ${ }^{*,+}$ \\ ${ }^{\dagger}$ Department of Chemistry, Center for Advanced Scientific Computing and Modeling (CASCaM), University of North Texas, Box \\ 305070, Denton, Texas 76203-5070, United States
}

Supporting Information

ABSTRACT: A computational study of the interaction of metal atoms $\left(\mathrm{M}^{\prime}\right)$ with cyclo- $[\mathrm{Au}(\mu-\mathrm{Pz})]_{3}$ trimer $(\mathrm{T})(\mathrm{Pz}=$ Pyrazolate ligand), a p-type organometallic semiconductor is reported in this article. The metal atoms chosen for the study are both high and low work function electrode metals $\left(\mathrm{M}^{\prime}=\mathrm{Al}, \mathrm{Au}, \mathrm{Cu}\right.$, $\mathrm{La}, \mathrm{Ni}, \mathrm{Pd}, \mathrm{Pt}, \mathrm{Ru}, \mathrm{Ni})$ used in electronic devices. Metal $\left(\mathrm{M}_{\mathrm{M}}^{\prime}\right)$ and ligand $\left(\mathrm{M}_{\mathrm{L}}^{\prime}\right)$ sites of the gold trimer are investigated as the possible sites of deposition for the metal atoms. Examination of metal binding, geometric, and electronic properties indicated

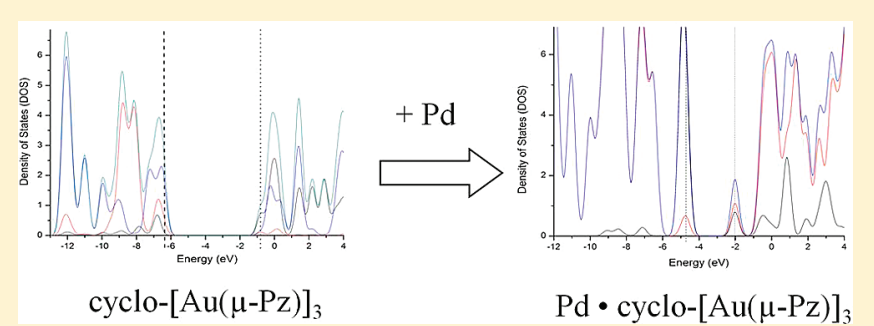
that low work function metals $\mathrm{La}$ and Ti favor the ligand coordination $\left(\mathrm{M}_{\mathrm{L}}^{\prime}\right)$; $\mathrm{Al}, \mathrm{Au}, \mathrm{Cu}, \mathrm{Ni}, \mathrm{Pt}$, and $\mathrm{Ru}$ favor coordination to the metal (i.e., gold) site of the trimer. Pd has equal stability at both the $\mathrm{M}_{\mathrm{L}}^{\prime}$ and the $\mathrm{M}_{\mathrm{M}}^{\prime}$ sites of the trimer. Changes in geometry of the trimer upon deposition of the metal atom are negligible for $\mathrm{M}_{\mathrm{M}}^{\prime}-\mathrm{T}$ complexes but more change is seen for $\mathrm{M}_{\mathrm{L}}^{\prime}-\mathrm{T}$ complexes. All metal atoms except Pd exhibited good orbital hybridization with the gold trimer in $\mathrm{M}^{\prime}-\mathrm{T}$ complexes. These combinations of observations suggest that, for these metal-based, p-type conductors will form stable interfaces with good electron transfer with typical source/drain electrode metals.

\section{INTRODUCTION}

A variety of trinuclear nine-membered rings with $\mathrm{Au}(\mathrm{I})$ ions and monoanionic bidentate ligands ( $\mathrm{L}$ ) of $\mathrm{C}-\mathrm{C}, \mathrm{C}-\mathrm{N}$, and $\mathrm{N}-\mathrm{N}$ ligation have been synthesized by several different groups over the past three decades. ${ }^{1-7}$ These trigold(I) complexes (cyclo- $\left.[\mathrm{Au}(\mu-\mathrm{L})]_{3}\right)$ (Figure 1 for a characteristic example) exhibit approximate $D_{3 h}$ symmetry. ${ }^{8}$ Aurophilic interactions result from a combination of correlation and relativistic effects ${ }^{9,10}$ and are generally marked by $\mathrm{Au}-\mathrm{Au}$ distances of less than $3.6 \AA$. Aurophilic interactions are partly responsible for the formation of a variety of $\mathrm{Au}_{3} \mathrm{~L}_{3}$ solid-state structures, for example, individual complexes, dimers of trimers, supramolecular stacks, and so forth. Many cyclo- $[\mathrm{Au}(\mu-\mathrm{L})]_{3}$ complexes exhibit remarkable properties such as $\pi$-acidity and basicity, luminescence, thermochromism, solvoluminescence, ${ }^{7,11,12}$ excimeric bonding, and thus find application in metal-organic electronics such as organic light emitting diodes (OLEDs), ${ }^{13}$ solar cells, photovoltaics, and metal organic field effect transistors (MOFETs). ${ }^{14}$

Many $\mathrm{d}^{10}$ transition metal (TM) pyrazolate $(\mathrm{Pz})$ trimers (cyclo- $\left.[\mathrm{TM}(\mu-\mathrm{Pz})]_{3}\right)$ have been synthesized with various organic substituents on the pyrazolate ligands. ${ }^{12,15}$ In collaboration with Omary's group, our own group has researched luminescence properties for cyclo- $[\mathrm{TM}(\mu-\mathrm{Pz})]_{3}$ trimers (where $\mathrm{TM}=$ $\mathrm{Ag}, \mathrm{Au}, \mathrm{Cu}$ ) with $-\mathrm{CF}_{3}$ substituents on pyrazolate ligands. ${ }^{7}$ It has been demonstrated via a combination of experiment and modeling that cyclo- $[\mathrm{Au}(\mu-\mathrm{Pz})]_{3}$ (Figure 1 ) is among the most $\pi$-basic of this family of coinage metal trimers. The $\pi$-acidity and $\pi$-basicity was assessed using molecular electrostatic potentials
(MEPs), HOMO (highest occupied molecular orbital) and LUMO (lowest unoccupied molecular orbital) energies, positive charge attraction energies, and so forth. The simulations revealed that cyclo- $[\mathrm{Au}(\mu-\mathrm{Pz})]_{3}$ trimers act as good $\pi$-bases and so should be good models for p-type conductors in molecular electronics. ${ }^{16}$ For example, we recently reported the synthesis, characterization and computational modeling of stacked trimers, $[\operatorname{Ag}(\mu-\mathrm{Tz}-(n$ $\left.\left.\left.\mathrm{C}_{3} \mathrm{~F}_{7}\right)_{2}\right)\right]_{3} \cdot\left[\mathrm{Au}\left(\mu \text {-Pz- }\left(i-\mathrm{C}_{3} \mathrm{H}_{7}\right)_{2}\right)\right]_{3}(\mathrm{Tz}=$ triazolate $)$, where the cyclo- $[\mathrm{Au}(\mu-\mathrm{Pz})]_{3}$ donor is a $\mathrm{p}$-type conductor in a $\mathrm{p}-\mathrm{n}$ blended material. ${ }^{17}$ In addition, cyclo- $[\mathrm{Au}(\mu-\mathrm{Pz})]_{3}$ complexes have also been used in applications that exploit their catalytic redox activity, metallomesogenic character, and photonic properties. ${ }^{18}$ Ref 12 summarizes gold(I) pyrazolate complexes.

In electronic devices, source and drain electrodes are usually metals and are important components in determining the performance of a device. ${ }^{19}$ Several metals have been tested or used as electrodes in electronic devices depending upon the type of conducting material, surrounding environment, surface chemistry with interacting materials and most importantly the right work function. Source and drain contacts are critical for effective charge transfer in electronic devices. In OLEDs, electrons and holes are injected from metal contacts into an organic or organometallic material where they subsequently recombine to emit light. Selection of metals with appropriate work functions is

\footnotetext{
Received: November 29, 2010

Revised: February 10, 2011

Published: March 10, 2011
} 


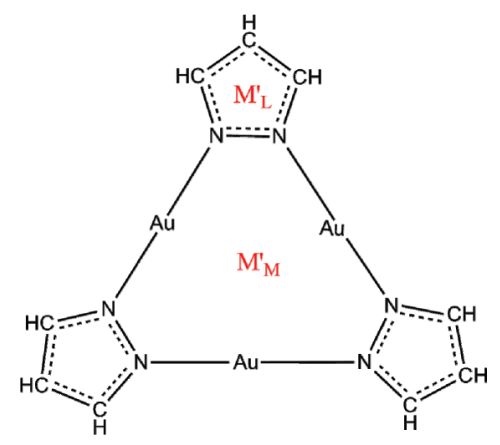

Figure 1. Structure of cyclo- $[\mathrm{Au}(\mu-\mathrm{Pz})]_{3}(\mathrm{Pz}=$ Pyrazolate $)$ trimer. $\mathrm{M}_{\mathrm{L}}^{\prime}$ and $\mathrm{M}_{\mathrm{M}}^{\prime}$ represent the ligand $(\mathrm{L})$ and metal $(\mathrm{M})$ deposition sites for different electrode metals $\left(\mathrm{M}^{\prime}\right)$ on the cyclo- $[\mathrm{Au}(\mu-\mathrm{Pz})]_{3}$ trimer.

thus essential to avoid any barrier between the contacts that can impede the flow of charge in the device. ${ }^{20}$ As the channel length decreases, the contact resistance between the source/drain electrodes and the semiconductor becomes increasingly important to device performance. ${ }^{21}$ Hence, understanding the geometric and electronic properties of the contacts and their dependence on electrode materials has become increasingly important for processing organic semiconductors as researchers seek to go from molecular level control of properties to a realworld device fabrication perspective.

In this article, the interaction of different electrode metal atoms $\left(\mathrm{M}^{\prime}\right)$ with cyclo- $[\mathrm{Au}(\mu-\mathrm{Pz})]_{3} \operatorname{trimer}(\mathrm{T})$ (Figure 1) is modeled. These electrode metals were chosen to assess metaltrimer interactions for $\mathrm{M}^{\prime}=\mathrm{Al}, \mathrm{Au}, \mathrm{Cu}, \mathrm{La}, \mathrm{Ni}, \mathrm{Pd}, \mathrm{Pt}, \mathrm{Ru}, \mathrm{Ni}$. All of these metals are currently used as electrodes in electronic devices. ${ }^{19}$ Modeling the interactions of atoms with semiconductors is an important first step in modeling full electrode metal surfaces because in a device there is the possibility of diffusion of metal atoms from the slab into the semiconductor layer causing instability and inferior device performance. Stability of the device is very important and can be modeled partly by studying the metal atom interactions with the semiconductor, as we have done in this article. Also, molecular calculations can help us better understand the type of bonding interactions that lead to charge transfer between interfaces.

\section{- COMPUTATIONAL METHODOLOGY}

Geometry optimizations and single point calculations of cyclo- $[\mathrm{Au}(\mu-\mathrm{Pz})]_{3}$ trimer and metal $\left(\mathrm{M}^{\prime}\right)$-trimer complexes are performed using the Gaussian09 program. ${ }^{22}$ Molecular DFT calculations are carried out with the B3LYP hybrid functional $^{23-25}$ in conjunction with the CEP-31G(d) pseudopotential basis set, ${ }^{26-28}$ where (d) signifies addition of a d-polarization function to main group elements. No imaginary frequencies are observed for the optimized structures, as confirmed by calculation of the energy Hessian. Also the spin contamination $\left(\left\langle S^{* *} 2\right\rangle\right.$ value) for the calculations is negligible $(<1 \%$ deviation) for all of the structures.

The B3LYP functional and basis set have been proven to be valuable for studying metallocyclic trimer compounds in many earlier studies and the geometries and energies correlate well with the experimental results. ${ }^{7,6,29}$ In addition, we also compared the geometries obtained from B3LYP with the B3PW91 $1^{30,31}$ hybrid functional (results not presented in the article) using the same basis set, which gave similar geometries for coinage

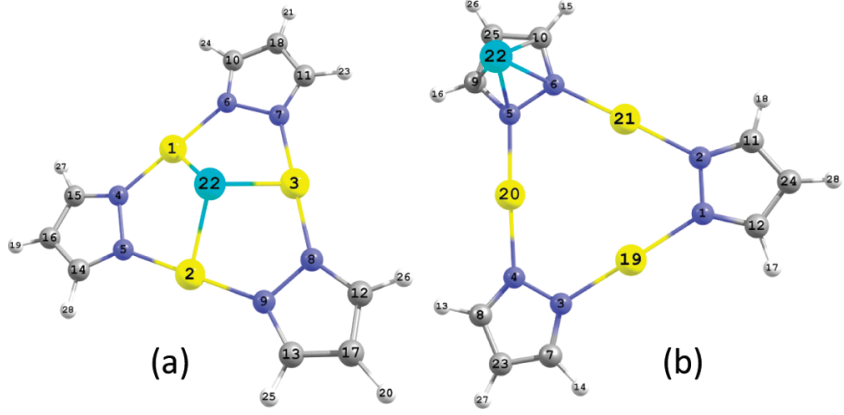

Figure 2. Possible deposition sites for metal atoms $\left(\mathrm{M}^{\prime}\right)$ on a cyclo- $[\mathrm{Au}(\mu-\mathrm{Pz})]_{3}$ trimer. The figure on the left and right represent the metal site $\left(\mathrm{M}_{\mathrm{M}}^{\prime}\right)$ and the ligand site $\left(\mathrm{M}_{\mathrm{L}}^{\prime}\right)$, respectively. The metal atoms are colored blue, gold - yellow, nitrogen - violet, carbon - gray, hydrogen - white. Each element is numbered in both the molecules (these numbers are later used to explain geometric properties).

metal - trimer complexes. In light of the study of Buhl et al. on the geometries of transition metal complexes with different DFT functionals, $^{32-34}$ we selected the B3LYP functional for the current study.

Molecular orbital occupancies and atomic charges are obtained by performing a natural population analysis (NPA) ${ }^{35,36}$ within the Gaussian suite of programs. The results from GaussianDFT calculations are utilized to plot the density of states (DOS) by expanding the atomic orbital occupancies using a Gaussian expansion scheme within the AOMix program. ${ }^{39,38}$ The full width at half-maximum (fwhm) value used in the Gaussian expansion scheme is $0.5 \mathrm{eV}$.

\section{RESULTS AND DISCUSSION}

Deposition of an electrode metal $\left(\mathrm{M}^{\prime}\right)$ on to cyclo- $[\mathrm{Au}(\mu$ $\mathrm{Pz})]_{3}$ trimer leads to two possible bonding sites (Figures 1 and 2): (a) a gold $\left(\mathrm{M}_{\mathrm{M}}^{\prime}\right)$ metallocycle binding site, or (b) an organic ligand $\left(\mathrm{M}_{\mathrm{L}}^{\prime}\right)$ site. Our goal is to assess the preference of protypical electrode metals of high and low work function for a metal or organic binding site with this p-type material. Additionally, the geometric relaxation of cyclo- $[\mathrm{Au}(\mu-\mathrm{Pz})]_{3}$ upon coordination of $\mathrm{M}^{\prime}$ is relevant to the efficiency of charge transfer across the electrode/conductor interface as well as the stability of the interface. A single metal atom, ligated in a $\pi$-type manner, that is coordinated the face of the $\mathrm{Au}_{3}$ triangle and a single $\mathrm{Pz}$ of the substrate, is utilized as a model. These choices are supported by experimental crystal structures of several metal/cyclo- $[\mathrm{M}(\mu$ $L)]_{3}$ ) structures that highlight the $\pi$-acid/base nature of these trimers. ${ }^{17}$ The former choice allows us to delineate metal/Au from organic/ $\mathrm{Pz}$ binding preferences, and is a necessary precursor to research on cyclo- $\left.[\mathrm{M}(\mu \text {-L })]_{3}\right)$ bound to various electrode metal surfaces.

One may expect that the metal atoms $\left(\mathrm{M}^{\prime}\right)$ used in the study may replace Au from the trimer $(\mathrm{T})$ skeleton and this could affect the stability of the $\mathrm{T}$ species for device applications. However, the experimental literature ${ }^{39}$ and expansion thereof to generalize the phenomenon, ${ }^{40}$ show that mixing of other metals like Ag, $\mathrm{Tl}, \mathrm{Na}$, $\mathrm{Li}$, and so forth with cyclo- $[\mathrm{Au}(\mu-\mathrm{L})]_{3}$ complexes attains $\pi$ complexes (as calculated here) rather than displacing one of the ring atoms. Furthermore, preliminary data by our device collaborators ${ }^{41}$ show that thermal deposition or solution casting of thin films of gold trimers on various metal cathodes retains the 
Table 1. Stability (eq 1) and Binding Energies (eq 3) for Metal-Trimer Complexes ${ }^{a}$

\begin{tabular}{|c|c|c|c|c|}
\hline $\mathrm{M}^{\prime}$ & spin state & $E_{\text {stability }}(\mathrm{eV})$ & stable binding site & binding energy $(\mathrm{eV})$ \\
\hline $\mathrm{Al}$ & 2 & 0.41 & M & -0.52 \\
\hline $\mathrm{Au}$ & 2 & 0.32 & M & -0.57 \\
\hline $\mathrm{Cu}$ & 2 & 0.43 & M & -0.63 \\
\hline $\mathrm{La}$ & 2 & -0.39 & $\mathrm{~L}$ & -0.73 \\
\hline $\mathrm{Ni}$ & 3 & 0.46 & M & -0.60 \\
\hline $\mathrm{Pd}(\mathrm{M} / \mathrm{L})$ & 1 & 0.00 & $\mathrm{M} / \mathrm{L}$ & $-0.85 /-0.85$ \\
\hline $\mathrm{Pt}$ & 3 & 0.28 & M & -0.60 \\
\hline $\mathrm{Ru}$ & 5 & 0.33 & M & -0.65 \\
\hline $\mathrm{Ti}$ & 3 & -0.70 & $\mathrm{~L}$ & -0.46 \\
\hline
\end{tabular}

${ }^{a} \mathrm{M}$ and $\mathrm{L}$ indicate metal and ligand binding sites, respectively. Only energies of the most stable sites of metal binding are summarized here. $\mathrm{Pd}$ is equally stable at either sites and denoted with $\mathrm{M} / \mathrm{L}$.

molecular structure of such cyclo- $[\mathrm{Au}(\mu-\mathrm{L})]_{3}$ trimer complexes, as evidenced by $\mathrm{IR}$ and photoluminescence data.

A) Metal Binding Characteristics. Geometry optimization of $\mathrm{M}^{\prime} /$ cyclo- $[\mathrm{Au}(\mu-\mathrm{Pz})]_{3}$ complexes at the two studied deposition sites for $\mathrm{M}^{\prime}$ on the $\mathrm{Au}$ trimer (Figure 2) is performed at the DFT level. The isolated cyclo-trimer has a singlet ground state. Hence, the spin multiplicity $(2 S+1)$ for all metal - trimer complexes $\left(\mathrm{M}^{\prime}-\mathrm{T}\right)$ considered here reflects the ground state multiplicity of $\mathrm{M}^{\prime}$.

The stability of electrode metals $\left(\mathrm{M}^{\prime}\right)$ at the gold trimer $(\mathrm{T})$ binding sites is determined from the total energy difference between the two isomeric binding sites of $\mathrm{M}^{\prime}-\mathrm{T}$, Figure 2 .

$$
E_{\text {stability }}=E_{\mathrm{L}}-E_{\mathrm{M}}
$$

The quantities $E_{\mathrm{L}}$ and $E_{\mathrm{M}}$ denote the total energies of metaltrimer complexes $\left(\mathrm{M}^{\prime}-\mathrm{T}\right)$ where $\mathrm{M}^{\prime}$ is ligated to the ligand $\left(\mathrm{M}_{\mathrm{L}}^{\prime}\right)$ and metal $\left(\mathrm{M}_{\mathrm{M}}^{\prime}\right)$ sites, respectively. $E_{\text {stability }}$ thus reflects the relative preference of $\mathrm{M}^{\prime}$ for the $\mathrm{M}_{M}^{\prime}$ site over $\mathrm{M}_{\mathrm{L}}^{\prime}$ site binding. In other words, if $E_{\text {stability }}<0, \mathrm{M}^{\prime}$ prefers to bind at the ligand site and vice versa for $E_{\text {stability }}>0$. All calculated $E_{\text {stability }}$ values are collected in Table 1 . The most stable site for $\mathrm{Al}, \mathrm{Au}$, $\mathrm{Cu}, \mathrm{Ni}, \mathrm{Pt}, \mathrm{Ru}$ is the metal site, as seen in Table 1. For La, Ti, the preferred binding site is the ligand site of the gold(I)-pyrazolate trimer; $E_{\text {stability }}=-0.39$ and $-0.70 \mathrm{eV}$, respectively. Interestingly, $\mathrm{Pd}$ has equal stability at both $\mathrm{M}_{\mathrm{L}}^{\prime}$ and $\mathrm{M}_{\mathrm{M}}^{\prime}$ sites, which is evidenced by $E_{\text {stability }}=0 \mathrm{eV}$.

i. Reoganization Energies Upon M' Coordination. Geometric distortion of the trimer $(\mathrm{T})$ upon $\mathrm{M}^{\prime}$ adsorption with respect to the original ground state geometry of the $\mathrm{M}^{\prime}$-free trimer is determined to give relaxation/reorganization (RO) energies $\left[E(\mathrm{~T})_{\mathrm{RO}}\right]^{42}$

$$
E(\mathrm{~T})_{\mathrm{RO}}=E(\mathrm{~T})_{\text {unrelaxed }}-E(\mathrm{~T})_{\text {relaxed }}
$$

The quantity $E(\mathrm{~T})_{\text {unrelaxed }}$ is the energy of the unrelaxed Au trimer at the $\mathrm{M}^{\prime}$-adsorbed geometry, $E(\mathrm{~T})_{\text {relaxed }}$ is the energy of the fully geometry optimized $\mathrm{Au}$ trimer in isolation. It is important to have low RO energies for better performance of a device, as large reorganization energies will retard efficient electron transfer in a device. ${ }^{42}$

All RO values are obtained from eq 2 and are very low, $<0.1 \mathrm{eV}$ $(2 \mathrm{kcal} / \mathrm{mol})$. Moreover, one expects an isolated metal atom to be more chemically reactive than a metal surface and thus the reorganization energies are likely to be even less for deposition of a cyclo-trimer on to an electrode metal surface. Hence, the
Table 2. Notable Bond Length Changes for Metal-Trimer

\begin{tabular}{|c|c|c|c|c|c|c|c|c|}
\hline bond $(\mathrm{R})$ type & $\mathrm{Al}$ & $\mathrm{Au}$ & $\mathrm{Cu}$ & $\mathrm{Ni}$ & $\mathrm{Pd}$ & $\mathrm{Pt}$ & $\mathrm{Ru}$ & $\sigma$ \\
\hline $\mathrm{Au}-\mathrm{M}_{\mathrm{M}}^{\prime} \quad \mathrm{R}(1-22)$ & 2.87 & 3.00 & 2.78 & 2.78 & 2.89 & 2.97 & 3.07 & 0.11 \\
\hline $\mathrm{Au}-\mathrm{M}_{\mathrm{M}}^{\prime} \quad \mathrm{R}(2-22)$ & 2.87 & 3.00 & 2.78 & 2.81 & 2.89 & 2.87 & 3.06 & 0.10 \\
\hline $\mathrm{Au}-\mathrm{M}_{\mathrm{M}}^{\prime} \quad \mathrm{R}(3-22)$ & 2.87 & 3.00 & 2.78 & 2.81 & 2.89 & 2.87 & 3.06 & 0.10 \\
\hline
\end{tabular}
Complexes at the $\mathbf{M}^{\prime}{ }_{M}$ Site $^{a}$

simulations suggest that electron transfer will be not be impeded by large structural reorganization of the conductor and should be efficient from the drain/source metals studied here to these p-type gold cyclo-trimer materials. One exception is calcium, which is a very low work function metal. Attempts to geometry optimize $\mathrm{Ca}-\mathrm{T}$ adducts lead to degradation of the organic ligand (data not shown), which suggests that electron transfer and interface stability would be compromised between calcium and this p-type organometallic.

ii. $M^{\prime}$ Binding Energies. The binding energy of the metal atom on the gold trimer is calculated as the difference in total energy between the optimized metal-trimer $\left(\mathrm{M}^{\prime}-\mathrm{T}\right)$ complex and the sum of energies of the isolated optimized trimer $(\mathrm{T})$ and metal atom $\left(\mathrm{M}^{\prime}\right)$. This energy is also called the metal adsorption energy.

$$
E_{\text {bind }}=\left(E_{\mathrm{M}-\mathrm{T}}\right)-\left(E_{\mathrm{M}}+E_{\mathrm{T}}\right)
$$

$E_{\text {bind }}$ is the binding energy of metal atom on the Au trimer and $E_{\mathrm{M}^{\prime}-\mathrm{T}}, E_{\mathrm{M}^{\prime}}, E_{\mathrm{T}}$ are the total energies of $\mathrm{M}^{\prime}$ - trimer complexes, $\mathrm{M}^{\prime}$ atoms and $\mathrm{Au}$ trimer, respectively. Examination of binding energy values (Table 1) reveals that $\mathrm{Ti}$ with $-0.46 \mathrm{eV}$ is the weakest binding and $\mathrm{Pd}$ with $-0.85 \mathrm{eV}$ is the strongest binding metal atom on the Au trimer. Also, it is interesting that Pd binds at both $\mathrm{M}_{\mathrm{L}}^{\prime}$ and $\mathrm{M}_{\mathrm{M}}^{\prime}$ sites with the same binding energy of $-0.85 \mathrm{eV}$.

Interaction of electrode metals with an organometallic semiconductor during device fabrication may result in diffusion of metal atoms into the semiconductor network. In this context, properties that characterize the stability of the metal/semiconductor interaction such as binding energies $\left(E_{\text {bind }}\right)$ are important to minimize impurity scattering within the device. The present simulations indicate strong binding, Table 2, of the electrode metal atoms to these p-type gold trimers and thus that they will form a stable interface with minimal diffusion.

B) Geometric Properties. For efficient performance of an electronic device, it is important for the different materials in the device to remain stable and be chemically compatible. Additionally, diffusion of one material to another, due to differences in chemical potential, is a common mechanism of failure in an electronic device. ${ }^{43-46}$ One way to judge the stability of a chemical system is by comparing the geometric changes in the system upon a chemical interaction. Trinuclear gold pyrazolate trimer is a nearly planar molecule, with average intramolecular $\mathrm{Au}-\mathrm{Au}$ distances ranging from $3.2-3.4 \AA^{4},{ }^{45}$ which indicate the $\mathrm{Au}-\mathrm{Au}$ interactions being in the aurophilic regime. Calculated $\mathrm{Au}-\mathrm{Au}$ distances in the geometry optimized gold pyrazolate trimer studied here is $3.44 \AA$, in good agreement with the experimental estimates.

We have analyzed the bond distances and bond angles for the gold trimer and each metal $\left(\mathrm{M}^{\prime}\right)$-trimer complex. Important bond distances are listed in Tables 2 and 3. The geometry of the $\mathrm{Au}$ trimer remains roughly unchanged for metals that are bound to the gold atoms $\left(\mathrm{M}_{\mathrm{M}}^{\prime}\right.$ site $)$. For example, the intramolecular 
Table 3. Comparison of Calculated Bond Distances with Experimental Bond Distances and Covalent Radii ${ }^{a}$

\begin{tabular}{|c|c|c|c|c|c|}
\hline metal & $\mathrm{R}\left(\mathrm{Au}-\mathrm{M}^{\prime}\right) \AA$ & $\begin{array}{c}\text { sum of } \\
\text { cov. radii } \AA\end{array}$ & $\mathrm{r}\left(\mathrm{Au}-\mathrm{M}^{\prime}\right) \AA$ & $\sigma\left(\mathrm{Au}-\mathrm{M}^{\prime}\right) \AA$ & $n$ \\
\hline & calcd & exptl & CCDC & CCDC & CCDC \\
\hline $\mathrm{Al}$ & 2.87 & 2.62 & & & \\
\hline $\mathrm{Au}$ & 3.00 & 2.88 & 2.94 & 0.19 & 3323 \\
\hline $\mathrm{Cu}$ & 2.78 & 2.82 & 2.79 & 0.13 & 102 \\
\hline $\mathrm{Ni}$ & 2.80 & 2.65 & 2.68 & 0.03 & 36 \\
\hline $\mathrm{Pd}$ & 2.89 & 2.75 & 2.82 & 0.14 & 201 \\
\hline $\mathrm{Pt}$ & 2.90 & 2.72 & 2.74 & 0.12 & 373 \\
\hline $\mathrm{Ru}$ & 3.06 & 2.70 & 2.81 & 0.08 & 412 \\
\hline
\end{tabular}

${ }^{a} r$ is the avg. bond length, $\sigma$ is the standard deviation, and $n$ is the sample size from CCDC. ${ }^{47}$.

Table 4. Notable Bond Length and Bond Angle Changes for Metal-Trimer Complexes at the $\mathbf{M}_{\mathrm{L}}^{\prime}$ Site $^{a}$

\begin{tabular}{lllcccc}
\multicolumn{2}{c}{ bond(R)/angle(A) type } & trimer & $\mathrm{La}$ & $\mathrm{Pd}$ & $\mathrm{Ti}$ & $\sigma$ \\
$\mathrm{M}^{\prime}-\mathrm{C} 3$ & $\mathrm{R}(22-9)$ & & 2.71 & 2.68 & 2.31 & 0.22 \\
$\mathrm{M}^{\prime}-\mathrm{C} 4$ & $\mathrm{R}(22-10)$ & & 2.71 & 2.68 & 2.31 & 0.22 \\
$\mathrm{M}^{\prime}-\mathrm{C} 9$ & $\mathrm{R}(22-25)$ & & 2.91 & 2.14 & 2.52 & 0.39 \\
$\mathrm{M}^{\prime}-\mathrm{N} 6$ & $\mathrm{R}(22-6)$ & & 2.45 & 3.34 & 2.07 & 0.65 \\
$\mathrm{M}^{\prime}-\mathrm{N} 5$ & $\mathrm{R}(22-5)$ & & 2.45 & 3.34 & 2.07 & 0.65 \\
$\mathrm{Au}-\mathrm{Au}$ & $\mathrm{R}(20-21)$ & 3.42 & 3.50 & 3.47 & 3.51 & 0.03 \\
$\mathrm{~N}-\mathrm{C}$ & $\mathrm{R}(5-9)$ & 1.36 & 1.45 & 1.35 & 1.44 & 0.05 \\
$\mathrm{~N}-\mathrm{C}$ & $\mathrm{R}(6-10)$ & 1.35 & 1.45 & 1.35 & 1.44 & 0.05 \\
$\mathrm{~N}-\mathrm{N}$ & $\mathrm{R}(5-6)$ & 1.38 & 1.51 & 1.39 & 1.49 & 0.07 \\
$\mathrm{~N}-\mathrm{Au}-\mathrm{N}$ & $\mathrm{A}(2-21-6)$ & 175.38 & 178.21 & 178.79 & 179.10 & 1.70 \\
$\mathrm{Au}-\mathrm{N}-\mathrm{C}$ & $\mathrm{A}(9-5-20)$ & 131.47 & 125.09 & 130.85 & 127.62 & 2.97 \\
$\mathrm{Au}-\mathrm{N}-\mathrm{C}$ & $\mathrm{A}(10-6-21)$ & 132.01 & 125.09 & 130.85 & 127.62 & 3.14
\end{tabular}

${ }^{a}$ The bond numbering is given according to part b of Figure 2. $\sigma$ is the standard deviation.

$\mathrm{Au}-\mathrm{Au}$ distances in all $\mathrm{M}^{\prime}-\mathrm{T}$ complexes with $\mathrm{M}^{\prime}{ }_{\mathrm{M}}$ coordination did not change significantly (maximum difference $=0.03 \AA$ or less than $1 \%)$ with respect to the parent structure cyclo- $[\mathrm{Au}(\mu-\mathrm{Pz})]_{3}$. The shortest $\mathrm{M}^{\prime}-\mathrm{Au}$ distance is seen for Ni (2.78 $\AA$ ), whereas the longest is for $\mathrm{Ru}(3.07 \AA)$, and roughly paralleling the size of the electrode metal atoms. Also, note from Table 2 that all three $\mathrm{M}^{\prime}-\mathrm{Au}$ distances are equivalent or nearly so, supporting the contention that metal binding occurs in a $\pi$-acid/base fashion as opposed to a $\pi$ /Lewis fashion.

Comparing our theoretical results for optimized $\mathrm{M}^{\prime}-\mathrm{Au}$ bond lengths with their respective covalent (Cov.) radii and experimental (Expt.) bond distance estimates (from the Cambridge Crystallographic Data Centre, (CCDC) database), ${ }^{47}$ is revealing with respect to the nature of the $\mathrm{M}^{\prime}-\mathrm{Au}$ interaction, Table 3 . The two coinage metals modeled $-\mathrm{Au}, \mathrm{Cu}-$ bind to the $\mathrm{M}_{\mathrm{M}}^{\prime}$ site at distances close to covalent bond estimates. However, earlier (Group 8 and 10) transition metals Ni, Pd, Pt, and Ru bind at $\mathrm{Au}-\mathrm{M}^{\prime}$ distances that are longer than covalent bond estimates, and hence lie toward the weaker van der Waals regime.

However, when metals are bound to the ligand $\left(\mathrm{M}_{\mathrm{L}}^{\prime}\right)$ site, the $\mathrm{Au}$ trimer structure changes more noticeably (Table 4), in comparison to the $\mathrm{M}^{\prime}{ }_{\mathrm{M}}$ binding site. Major differences in bond distances and angles can be seen on the ligand to which the metal $\left(\mathrm{M}^{\prime}\right)$ is bound (Table 4).

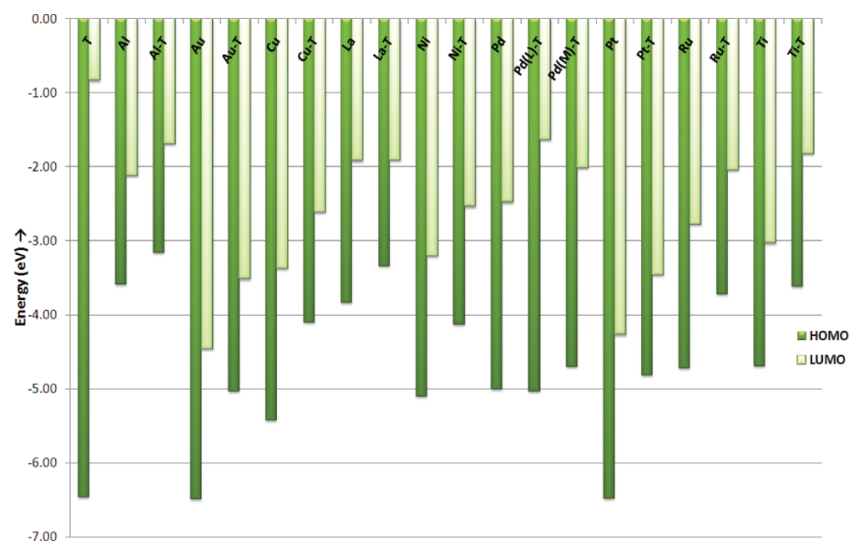

Figure 3. HOMO-LUMO values for Au trimer ( $\mathrm{T})$, individual metals $\left(\mathrm{M}^{\prime}\right)$ and stable metal-trimer complexes $\left(\mathrm{M}^{\prime}-\mathrm{T}\right)$ in $\mathrm{eV}$.

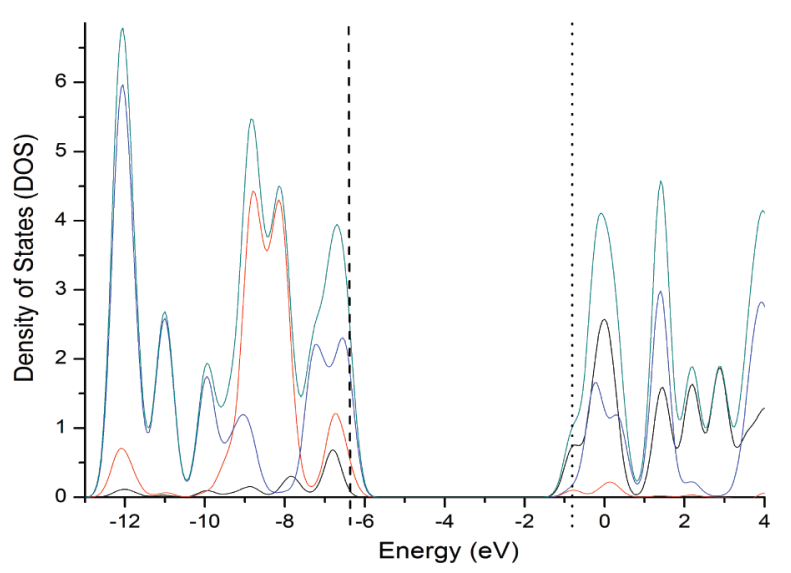

Figure 4. Projected DOS plot with contributions from gold $s+p, d$ orbitals and ligand orbitals colored in black, red, and blue, respectively. The total DOS is colored in green.

$\mathrm{La}$ and Ti metals cause an elongation of $\mathrm{N}-\mathrm{N}, \mathrm{N}-\mathrm{C}$ bonds, $\mathrm{N}-$ $\mathrm{Au}-\mathrm{N}$ bond angle, and shrinkage of $\mathrm{Au}-\mathrm{N}-\mathrm{C}$ bond angles on the ligand to which $\mathrm{La}$ and $\mathrm{Ti}$ are bonded. The average $\mathrm{N}-\mathrm{N}, \mathrm{N}-\mathrm{C}$ bonds and $\mathrm{N}-\mathrm{Au}-\mathrm{N}$ bond angle are elongated from $1.38 \AA$, $1.35 \AA$, and $175.4^{\circ}$ to $1.50 \AA, 1.44 \AA$, and $178.6^{\circ}$, respectively. The $\mathrm{Au}-\mathrm{N}-$ $\mathrm{C}$ bond angle reduces from $131.7^{\circ}$ to $126.4^{\circ}$. Also, the intramolecular $\mathrm{Au}-\mathrm{Au}$ distance increases by $0.08 \AA$ for the gold atoms that are bonded to the ligand to which $\mathrm{M}^{\prime}$ is $\pi$-coordinated. Both of these electropositive (low work function) metals are closer to the $\mathrm{N}$ atoms of the pyrazolate ligand than $\mathrm{C}$ atoms, which is consistent with the greater electronegativity of $\mathrm{N}$ versus $\mathrm{C}$.

Palladium binding to an $\mathrm{L}$ site behaves differently from $\mathrm{La}$ and Ti. No major change in the trimer geometry is seen when $\mathrm{Pd}$ binds to the ligand except for slight elongation of intramolecular $\mathrm{Au}-\mathrm{Au}$ distance from $3.42 \AA$ to $3.47 \AA$ for the gold atoms that are bonded to the pyrazolate to which Pd is bound. Also, Pd lies close to the tip carbon (C9 in part b of Figure 2) of the 5 membered pyrazolate ligand $\left(\eta^{1}-\mathrm{C}\right.$ coordination) in contrast to Ti and La, which are $\eta^{2}-\mathrm{N}, \mathrm{N}$.

Overall, examination of all geometric parameters of $\mathrm{Au}$ trimer and metal $\left(\mathrm{M}^{\prime}\right)$-trimer complex indicate that when $\mathrm{M}^{\prime}$ bind to the metal $\left(\mathrm{M}_{\mathrm{M}}^{\prime}\right)$ site no inordinate change in trimer structure is seen. On the contrary, $\mathrm{M}^{\prime}$ binding to the ligand $\left(\mathrm{M}_{\mathrm{L}}^{\prime}\right)$ site causes bending of the pyrazolate thus leading to considerable geometric distortion of $\mathrm{Au}$ trimer in contrast to its prototype. This is 

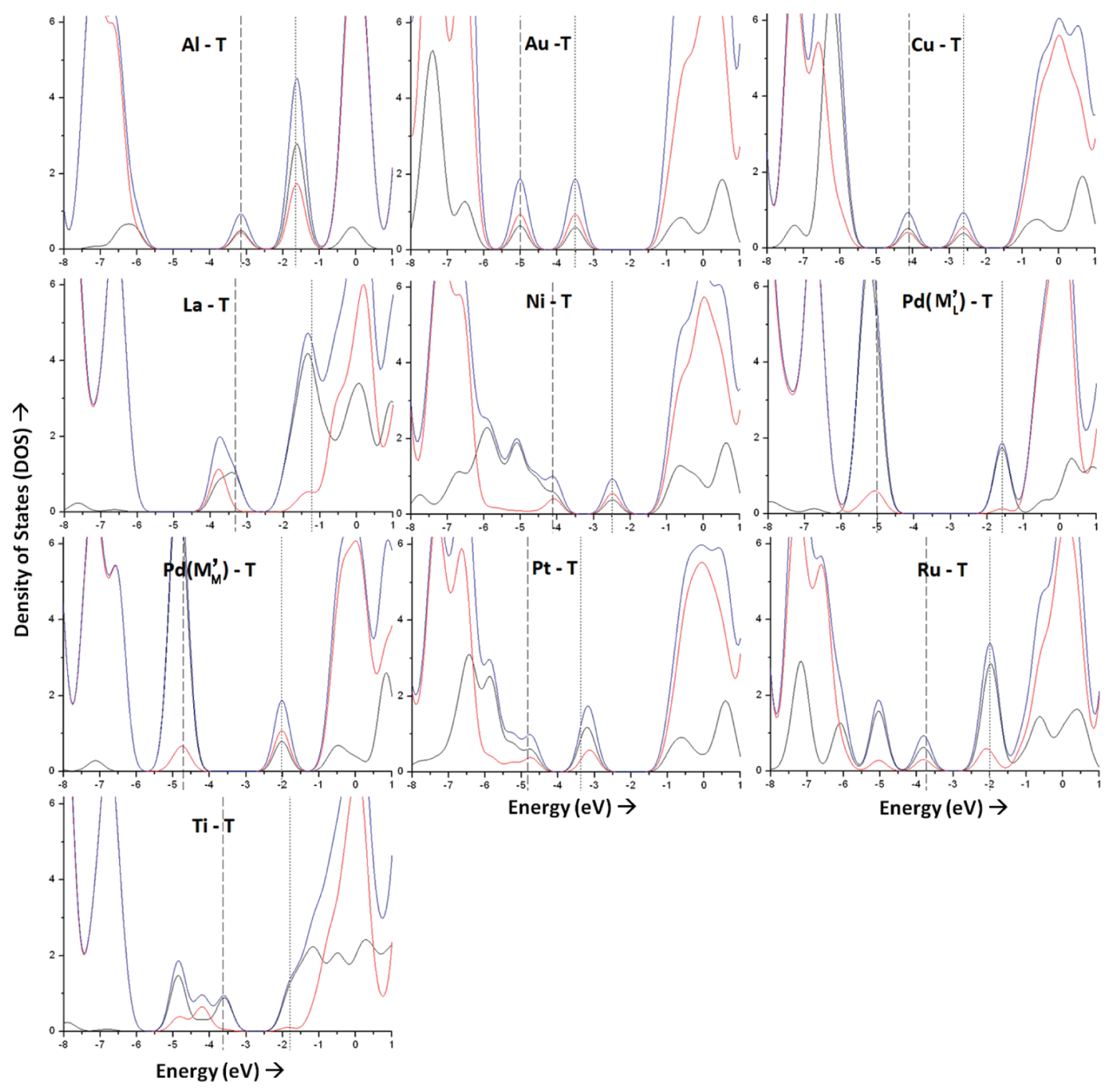

Figure 5. B3LYP DOS plots of metal-trimer complexes with metal atoms $\mathrm{M}^{\prime}=\mathrm{Al}, \mathrm{Au}, \mathrm{Cu}, \mathrm{La}, \mathrm{Ni}, \mathrm{Pd}, \mathrm{Pt}, \mathrm{Ru}, \mathrm{Ti}$. DOS plots for all the metals are limited to their stable sites, either the ligand $\left(\mathrm{M}_{\mathrm{L}}^{\prime}\right)$ or metal $\left(\mathrm{M}_{\mathrm{M}}^{\prime}\right)$ site. Two DOS plots are plotted for Pd, which is equally stable at both the sites and respective plots are named with $\mathrm{M}_{\mathrm{L}}^{\prime} / \mathrm{M}_{\mathrm{M}}^{\prime}$ in parentheses. The TDOS is colored blue, PDOS of metal atom $\left(\mathrm{M}^{\prime}\right)$ and trimer $(\mathrm{T})$ are colored black and red, respectively. The dashed lines mark the HOMOs and the dotted lines LUMOs for each complex.

however not seen for ligand bound $\mathrm{Pd}-$ trimer complex. In light of the overall low geometric reorganization, and strong interactions between the metal atoms and the trimer, the possibility of diffusion of metal atoms through the interfaces upon differences in chemical potential would be less and this phenomenon is important for a stable device performance. ${ }^{43-45}$

C) Electronic Properties. For investigation of the electronic structures of metal-trimer complexes, we plotted the HOMOLUMO energies and the atomic density of states (DOS) of all of the complexes have been analyzed. The HOMO-LUMO gap for the gold trimer is about $5.6 \mathrm{eV}$. Although this gap is large (and likely overestimated by these hybrid DFT calculations), electron donating substituents on the pyrazolate ligand reduce the HOMO-LUMO gap and make the trimer a conductor. ${ }^{16}$ Here, our primary concern is the change in electronic properties of the prototype structure of cyclo- $[\mathrm{Au}(\mu-\mathrm{Pz})]_{3}$ upon the coordination of typical electrode metals, $\mathrm{M}^{\prime}$.

Figure 3 presents the HOMO and LUMO values of all the stable metal-trimer complexes, metals and trimer. From the figure, it is clear that that the HOMO-LUMO gap decreases for all the $\mathrm{M}^{\prime}-\mathrm{T}$ complexes in contrast to the $\mathrm{T}$ alone. The largest and smallest HOMO-LUMO gaps of 3.4 and $1.5 \mathrm{eV}$ are calculated for $\mathrm{Pd}\left(\mathrm{M}_{\mathrm{L}}^{\prime}\right)-\mathrm{T}$ and $\mathrm{Pt}-\mathrm{T}$ complexes, respectively. The reduction in HOMO-LUMO gap is a result of both lowering the LUMO energy and raising the HOMO energy. As such, this suggests extensive $\mathrm{Au}-\mathrm{M}^{\prime}$ hybridization (see also corroborating DOS data below). Hence, the calculations predict that deposition of the trimer, $\mathrm{T}$, onto an electrode metal $\mathrm{M}^{\prime}$ will maintain if not improve conductivity properties across the electrode/conductor interface.

We also examined other electronic properties, namely charge transfer (CT) and dipole moment data for the Au trimer versus the $\mathrm{M}^{\prime}-\mathrm{T}$ complexes. CT was assessed using both Mulliken and Natural Population Analysis. Examination of all CT and dipole moment data did not reveal any obvious trend in terms of the binding preference of the electrode metal, $\mathrm{M}^{\prime}$, to either the metal or ligand sites of the gold trimer.

The orbital contributions or partial density of states (pDOS) of the trimer by itself and metal $\left(\mathrm{M}^{\prime}\right)$ projections to the total DOS ( $\mathrm{tDOS}$ ) of metal-trimer complexes are shown in Figure 4 
and Figure 5 (next page), respectively. The DOS results are obtained from the Gaussian expansion scheme of discrete energy levels $\varepsilon_{\mathrm{i}}$ by the AOMix code. . $^{3,38}$

$$
\operatorname{tDOS}(E)=\sum_{\mathrm{i}} \delta\left(E-\varepsilon_{\mathrm{i}}\right)
$$

$E$ is the energy at each state, $\varepsilon_{\mathrm{i}}$ is the one electron energy level, and $\delta$ is the Gaussian expansion function. Partial densities of states (pDOS) for fragments (group of atoms or orbitals) are determined using the Mulliken population analysis (MPA) scheme.

$$
\operatorname{pDOS}(E)=\sum_{\mathrm{i}} C_{\mathrm{A}, \mathrm{i}} \delta\left(E-\varepsilon_{\mathrm{i}}\right)
$$

$C_{\mathrm{A}, \mathrm{i}}$ is the one-electron character of any fragment $\mathrm{A}$ at energy $\varepsilon_{\mathrm{i}}$. The DOS plots gives an indication of which electrons hybridize in the metal trimer interaction and also helps in understanding the conduction or flow of charge near the metal-trimer interface.

Figure 4 shows the DOS plot of cyclo- $[\mathrm{Au}(\mu-\mathrm{Pz})]_{3}$ along with projections for the gold $6 \mathrm{~s}, 6 \mathrm{p}, 5 \mathrm{~d}$, and ligand orbitals. The $\mathrm{HOMO}$ and LUMO are at $-6.47 \mathrm{eV}$ and $-0.83 \mathrm{eV}$ respectively, yielding a $5.64 \mathrm{eV}$ HOMO-LUMO gap. The $\mathrm{pDOS}$ projections clearly indicate that pyrazolate ligands (blue line in Figure 4) are major contributors in both the HOMO (valence) and LUMO (conduction) orbitals. Also, the valence band has considerable gold $5 \mathrm{~d}$ orbital character (red line in Figure 4) with some $\mathrm{s}$ and $\mathrm{p}$ character. The above interpretation is consistent with previous studies of similar coinage metal materials. ${ }^{17}$

Figure 5 shows the DOS plots of all $\mathrm{M}^{\prime}-\mathrm{T}$ complexes studied here. For all $\mathrm{M}^{\prime}-\mathrm{T}$ complexes, the HOMO and LUMO energies rise (become more weakly bound) and fall respectively with respect to those of isolated cyclo- $[\mathrm{Au}(\mu-\mathrm{Pz})]_{3}$. This phenomenon highlights the hybridization of the metal orbitals with those of gold. The degree of hybridization however varies for different metal atoms. Among all the DOS plots, the DOS for the $\mathrm{Pd}-\mathrm{T}$ complex is distinct. The orbital mixing or hybridization of metal atoms with trimer based orbitals is less for Pd at both the gold and pyrazolate binding sites, which can be seen from the wide HOMO-LUMO gap and pDOS plots of $\operatorname{Pd}\left(\mathrm{M}_{\mathrm{L}}^{\prime}\right)-\mathrm{T}$ and $\mathrm{Pd}$ $\left(\mathrm{M}_{\mathrm{M}}^{\prime}\right)-\mathrm{T}$. In either case, very little or no contribution from the Pd atom (black line in the graph, Figure 5) is seen in DOS plots. However, all of the remaining metal atoms show considerable mixing of $M^{\prime}$ orbitals with gold trimer, where the atomic contribution of the electrode metals is clearly seen in the respective DOS plots (Figure 5).

Examining individual DOS plots of $\mathrm{M}^{\prime}-\mathrm{T}$ complexes gives an overview of how different metals contribute to tDOS. We focus our discussion mostly to the frontier/Fermi level orbitals in the vicinity of the HOMO and LUMO (ca. -8 to $1 \mathrm{eV}$ energy), which would be responsible for most chemical reactions and charge transport. The $\mathrm{pDOS}$ plot of $\mathrm{Al}-\mathrm{T}$ complex shows equal contributions from $\mathrm{Al}$ and trimer to the HOMO, whereas the trimer orbitals dominate the LUMO. In the $\mathrm{Au}-\mathrm{T}$ complex, the contribution of the bound gold atom is roughly the same in the valence and conduction bands, but remains less than the contribution of orbitals from the trimer. The $\mathrm{Cu}$ character in $\mathrm{Cu}-\mathrm{T}$ complex is similar to that of gold in $\mathrm{Au}-\mathrm{T}$. The pDOS plots show considerable orbital mixing at the top of the valence band, but the $\mathrm{Cu}$ character is less in the conduction band, as seen in Figure 5.
For the $\mathrm{La}-\mathrm{T}$ complex (recall La binds to the $\mathrm{L}$ site), the $\mathrm{La}$ contribution to the HOMO is prominent but orbitals below the HOMO have very low or no contribution from La. Unlike the coinage metals just discussed, the La character is high in the LUMO and the orbitals beyond. The DOS plot of Ti-T complex (recall that Ti binds to the L site), Figure 5, is similar to that of $\mathrm{La}-\mathrm{T}$ complex, where $\mathrm{Ti}$ character is less in orbitals below HOMO and more in orbitals above the LUMO. The trimer contribution to HOMO and LUMO orbitals is negligible indicating that HOMO and LUMO orbitals in $\mathrm{Ti}-\mathrm{T}$ complex are solely from Ti metal atom.

The pDOS plots of the $\mathrm{Ni}-\mathrm{T}$ complex shows ample mixing of metal atom and trimer orbitals, Figure 5, within the range considered which is apparent from the $\mathrm{Ni}$ character in the DOS. $\mathrm{Pt}-\mathrm{T}$ and $\mathrm{Ru}-\mathrm{T}$ complexes are similar to $\mathrm{Ni}-\mathrm{T}$ complexes where notable mixing of orbitals is seen and there is metal $\left(\mathrm{M}^{\prime}\right)$ atom contribution in both the HOMO and LUMO.

Analyzing the binding preferences of metal atoms on the trimer, electropositive transition metals La, Ti prefer the anionic $\mathrm{M}_{\mathrm{L}}^{\prime}$ site in contrast to electronegative $\mathrm{Au}, \mathrm{Cu}, \mathrm{Ni}, \mathrm{Pt}$, and $\mathrm{Ru}$, which prefer the cationic $\mathrm{M}_{\mathrm{M}}^{\prime}$ site. The reason for equal gold/ ligand binding preferences of the $\mathrm{Pd}$ atom is not understood, but may be related to its different frontier orbital composition, which shows minimal hybridization with trimer orbitals. Al, which is the only main group element in our list, binds to the $\mathrm{M}_{\mathrm{M}}^{\prime}$ site.

\section{- SUMMARY AND CONCLUSIONS}

Molecular DFT calculations are performed on cyclo- $[\mathrm{Au}(\mu$ $\mathrm{Pz})]_{3}$ trimer $(\mathrm{T})$, a model p-type organometallic, with prototypical electrode metal atoms $\left(\mathrm{M}^{\prime}\right)$. Metal $\left(\mathrm{M}_{\mathrm{M}}^{\prime}\right)$ and ligand $\left(\mathrm{M}_{\mathrm{L}}^{\prime}\right)$ sites of the gold trimer are investigated as the possible sites of deposition for the metal atoms. Metal atom-trimer $\left(\mathrm{M}^{\prime}-\mathrm{T}\right)$ interactions for $\mathrm{M}^{\prime}=\mathrm{Al}, \mathrm{Au}, \mathrm{Cu}, \mathrm{La}, \mathrm{Ni}, \mathrm{Pd}, \mathrm{Pt}, \mathrm{Ru}$, and $\mathrm{Ni}$ are presented in this report. Metal binding characteristics, geometric and electronic properties were analyzed for $\mathrm{M}^{\prime}-\mathrm{T}$ complexes. It was found that $\mathrm{Al}, \mathrm{Au}, \mathrm{Cu}, \mathrm{Ni}, \mathrm{Pt}$, and $\mathrm{Ru}$ favor coordination to the metal (i.e., gold) site of the trimer; low work function metals like La and Ti favor the ligand site, whereas Pd has equal stability at both the $\mathrm{M}_{\mathrm{L}}^{\prime}$ and the $\mathrm{M}_{\mathrm{M}}^{\prime}$ sites of the trimer. Among all of the metal-atoms, $\mathrm{Ti}$ is the weakest binding and $\mathrm{Pd}$ is the strongest binding to the Au trimer at their respective stable coordination sites. Changes in geometry of the trimer upon deposition of metal atom are negligible for $\mathrm{M}_{\mathrm{M}}^{\prime}-\mathrm{T}$ complexes but more change is seen for $\mathrm{M}_{\mathrm{L}}^{\prime}-\mathrm{T}$ complexes. Examination of the electronic structure of all $\mathrm{M}^{\prime}-\mathrm{T}$ complexes reveal a considerable hybridization for all $\mathrm{M}^{\prime}$ and trimer orbitals around the HOMO and LUMO. However, there is an exception for $\mathrm{Pd}-\mathrm{T}$ complex where negligible $\mathrm{Pd}$ contribution is observed around the HOMO-LUMO.

In conclusion, modeling the effect of electrode metal atom deposition onto a p-type gold trimer is important to understand the impact of metal-trimer chemistry upon the electronic properties of cyclo- $\mathrm{Au}(\mu-\mathrm{L})]_{3} \cdot{ }^{7,11,12}$ Deposition of metal source and drain electrodes on the organometallic semiconductor during device fabrication is critical for stable device performance. Metal binding characteristics, as well as geometric and electronic properties, play an important role in minimizing impurity scattering within the device. Efficient charge transport across the metal-trimer interface is also critical as researchers seek to go from molecular level control of properties to real-world device fabrication perspectives. The present simulations indicate 
minimal reorganization, both in terms of the energies and geometries, upon metal/trimer interaction. The substantial binding energies of the electrode metal atoms to the p-type trimer, significant hybridization of the metal and trimer orbitals near the Fermi level, and large changes in the HOMO-LUMO gaps upon metal deposition all suggest a stable interface for these metal-based MOFETs, with efficient charge transport, for both high and low work function metals.

\section{ASSOCIATED CONTENT}

S Supporting Information. Geometric data, population analysis, dipole moments, and Cartesian coordinates. This material is available free of charge via the Internet at http:// pubs.acs.org.

\section{AUTHOR INFORMATION}

\section{Corresponding Author}

*E-mail: tomc@unt.edu.

\section{ACKNOWLEDGMENT}

T.R.C. thanks National Science Foundation (CHE-0911690) and the Texas Advanced Research Program (009741-00892007) for support. Calculations employed the UNT computational chemistry resource, supported by the NSF through grant CHE-0741936.

\section{REFERENCES}

(1) Vaughan, L. G. J. Am. Chem. Soc. 1970, 92, 730-731.

(2) Parks, J. E.; Balch, A. L. J. Organomet. Chem. 1974, 71, 453-463.

(3) Minghetti, G.; Bonati, F. Inorg. Chem. 1974, 13, 1600-1602.

(4) Bovio, B.; Bonati, F.; Banditelli, G. Inorg. Chim. Acta 1984, $87,25-33$.

(5) Bovio, B.; Calogero, S.; Wagner, F. E.; Burini, A.; Pietroni, B. R. J. Organomet. Chem. 1994, 470, 275-283.

(6) Balch, A. L.; Olmstead, M. M.; Vickery, J. C. Inorg. Chem. 1999, 38, 3494-3499.

(7) Omary, M. A.; Rawashdeh-Omary, M.; Gonser, M. W. A.; Elbjeirami, O.; Grimes, T.; Cundari, T. R.; Diyabalanage, H. V. K.; Gamage, C. S. P.; Dias, H. V. R. Inorg. Chem. 2005, 44, 8200-8210.

(8) Burini, A.; Mohamed, A. A.; Fackler, J. P. Comments Inorg. Chem. 2003, 24, 253.

(9) Pyykkö, P.; Zhao, Y. Angew. Chem., Int. Ed. 1991, 30, 604-605.

(10) Pyykkö, P.; Li, J.; Runeberg, N. Chem. Phys. Lett. 1994, 218, 133-138.

(11) Dias, H. V. R.; Diyabalanage, H. V. K.; Rawashdeh-Omary, M.; Franzman, M. A.; Omary, M. A. J. Am. Chem. Soc. 2003, 125, 12072-12073.

(12) Dias, H. V. R.; Diyabalanage, H. V. K.; Eldabaja, M. G.; Elbjeirami, O.; Rawashdeh-Omary, M.; Omary, M. A. J. Am. Chem. Soc. 2005, 127, 7489-7501.

(13) D'AndradeB., W.; Forrest, S. R. Adv. Mater. 2004, $16,1585-1595$.

(14) Caseri, W. R.; Chanzy, H. D.; Feldman, K.; Fontana, M.; Smith, P.; Tervoort, T. A.; Goossens, J. G. P.; Meijer, E. W.; Schenning, A. P. H. J.; Dolbnya, I. P.; Debije, M. G.; de Haas, M. P.; Warman, J. M.; van de Craats, A. M.; Friend, R. H.; Sirringhaus, H.; Stutzmann, N. Adv. Mater. 2003, 15, 125-129.

(15) Torralba, M. C.; Ovejero, P.; Mayoral, M. J.; Cano, M.; Campo, J.; Heras, J.; Pinilla, E.; Torres, M. R. Helv. Chim. Acta 2004, 87, 250-263.

(16) Tekarli, S. M.; Cundari, T. R.; Omary, M. A. J. Am. Chem. Soc. 2008, 130, 1669-1675.
(17) Chilukuri, B.; Cundari, T. R.; Omary, M. A.; Gnade, B. In In Modeling silver and gold complexes for next generation electronic materials; Abstracts of Papers, INOR 363; poster presentation to the ACS Division of Inorganic Chemistry,239th ACS National Meeting, San Francisco, CA, Mar 21-25, 2010; American Chemical Society: Washington, D.C., 2010.

(18) Kim, S. J.; Kang, S. H.; Park, K.; Kim, H.; Zin, W.; Choi, M.; Kim, K. Chem. Mater. 1998, 10, 1889-1893.

(19) Zaumseil, J.; Sirringhaus, H. Chem. Rev. 2007, 107, 1296-1323.

(20) Campbell, I. H.; Rubin, S.; Zawodzinski, T. A.; Kress, J. D.; Martin, R. L.; Smith, D. L.; Barashkov, N. N.; Ferraris, J. P. Phys. Rev. B 1996, 54, R14321.

(21) Zaumseil, J.; Baldwin, K. W.; Rogers, J. A. J. Appl. Phys. 2003, 93, 6117-6124.

(22) Frisch, M. J.; et al. Gaussian 09, Revision A.1; Gaussian, Inc.: Wallingford CT, 2009.

(23) Stephens, P. J.; Devlin, F. J.; Chabalowski, C. F.; Frisch, M. J. J. Phys. Chem. 1994, 98, 11623-11627.

(24) Becke, A. D. Phys. Rev. A 1988, 38, 3098.

(25) Lee, C.; Yang, W.; Parr, R. G. Phys. Rev. B 1988, 37, 785.

(26) Stevens, W. J.; Krauss, M.; Basch, H.; Jasien, P. G. Can. J. Chem. 1992, 70, 612 .

(27) Stevens, W. J.; Basch, H.; Krauss, M. J. Chem. Phys. 1984, $81,6026-6033$.

(28) Cundari, T. R.; Stevens, W. J. J. Chem. Phys. 1993, 98, 5555-5565.

(29) Grimes, T.; Omary, M. A.; Dias, H. V. R.; Cundari, T. R. J. Phys. Chem. A 2006, 110, 5823-5830.

(30) Becke, A. D. J. Chem. Phys. 1996, 98, 5648-5642.

(31) Perdew, J. P.; Wang, Y. Phys. Rev. B 1992, 45, 13244-13249.

(32) Buhl, M.; Kabrede, H. J. Chem. Theory Comput. 2006, 2, 1282-1290.

(33) Waller, M. P.; Braun, H.; Hojdis, N.; Buhl, M. J. Chem. Theory Comput. 2007, 3, 2234-2242.

(34) Buhl, M.; Reimann, C.; Pantazis, D. A.; Bredow, T.; Neese, F. J. Chem. Theory Comput. 2008, 4, 1449-1459.

(35) Foster, J. P.; Weinhold, F. J. Am. Chem. Soc. 1980, $102,7211-7218$.

(36) Reed, A. E.; Weinstock, R. B.; Weinhold, F. J. Chem. Phys. 1985, $83,735-746$.

(37) Gorelsky, S. I. AOMix program, http://www.sg-chem.net/.

(38) Gorelsky, S. I.; Lever, A. B. P. J. Organomet. Chem. 2001, $635,187-196$

(39) Burini, A.; Bravi, R.; Fackler, John P.; Galassi, R.; Grant, T. A.; Omary, M. A.; Pietroni, B. R.; Staples, R. J. Inorg. Chem. 2000, $39,3158-3165$.

(40) Omary, M. A. et al. , Abstracts of Papers, INOR-119; presentation to the ACS Division of Inorganic Chemistry, 236th ACS National Meeting, Philadelphia, PA, Aug 17-21, 2008; American Chemical Society: Washington, DC., 2010.

(41) Gnade, B. (University of Texas, Dallas); Omary, M. A (University of North Texas) - private communication.

(42) Marcus, R. A. Rev. Mod. Phys. 1993, 65, 599.

(43) Aziz, H.; Popovic, Z. D.; Hu, N.; Hor, A.; Xu, G. Science 1999, 283, 1900-1902.

(44) Chua, S.; Ke, L.; Kumar, R. S.; Zhang, K. Appl. Phys. Lett. 2002, $81,1119-1121$.

(45) Cumpston, B. H.; Jensen, K. F. Appl. Phys. Lett. 1996, 69, 3941-3943.

(46) Diao, L.; Frisbie, C. D.; Schroepfer, D. D.; Ruden, P. P. J. Appl. Phys. 2007, 101, 014510-8.

(47) Allen, F. Acta Crystallogr. 2002, 58, 380-388. 